\title{
Late recovery of atrioventricular conduction after pacemaker implantation for complete heart block in congenital heart disease: fact or fluke ?*
}

\section{J. De Raet, F. Rega \& B. Meyns}

To cite this article: J. De Raet, F. Rega \& B. Meyns (2010) Late recovery of atrioventricular conduction after pacemaker implantation for complete heart block in congenital heart disease: fact or fluke ?*, Acta Chirurgica Belgica, 110:3, 323-327, DOI: 10.1080/00015458.2010.11680625

To link to this article: https://doi.org/10.1080/00015458.2010.11680625

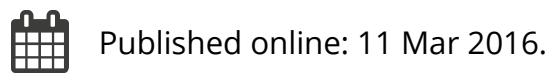

Submit your article to this journal ๔a

W Article views: 4

a)

View related articles $\sqsubset$

Citing articles: 3 View citing articles $₫$ 


\title{
Case reports
}

Acta Chir Belg, 2010, 110, 323-327

\section{Late recovery of atrioventricular conduction after pacemaker implantation for complete heart block in congenital heart disease : fact or fluke ?*}

\author{
J. De Raet, F. Rega, B. Meyns
}

Department of Pediatric and Congenital Cardiac Surgery, University Hospitals Leuven, Herestraat 49, 3000 Leuven, Belgium.

Key words. Complete heart block ; congenital heart disease ; late recovery ; pacemaker ; pediatric cardiac surgery.

\begin{abstract}
Objectives : Pacemaker implantation is a standard recommendation for patients with persistent complete heart block with congenital heart disease. This study was performed to determine the incidence and clinical significance of late recovery of atrioventricular (AV) conduction following pacemaker implantation.

Methods: A retrospective study of patients with congenital heart disease needing pacemaker implantation was performed between 1977 and 2008 at our institution. The postoperative course of all patients with complete heart block, in whom a permanent pacemaker was implanted, was followed on a semi-annual basis by clinical follow-up.

Results : A total of 56 patients with complete heart block underwent pacemaker implantation. Indications for pacemaker implantation could be categorized in primary AV conduction block $(\mathrm{n}=28 ; 50 \%)$ and surgically-induced AV conduction block $(\mathrm{n}=28 ; 50 \%)$. After pacemaker insertion, recovery of AV conduction was recognized in two patients. The first patient was operated for atrial septal defect type ostium secundum with complete heart block preoperatively. AV block resolved 2 days after pacemaker implantation. The second patient underwent mitral valve replacement. Postoperatively, the patient developed second degree heart block, which progressed 3 years later into complete heart block. A recovery of AV conduction was seen 7.5 years later. In these patients, no late recurrence of complete heart block was found during follow-up after 8 and 4 months, respectively.

Conclusions : Recovery of AV conduction was observed in one patient with primary AV conduction block and in one patient with complete heart block after congenital heart surgery. Lifelong cardiac pacing in these specific subsets of patients may not be necessary.
\end{abstract}

\section{Introduction}

Complete heart block (CHB), also known as third-degree AV conduction block, is a condition in which the impulse, generated in the sino-atrial node in the atrium, does not propagate to the ventricles. In the pediatric population, $\mathrm{CHB}$ may be due to a primary congenital heart disease or be secondary to congenital heart surgery. The cause of congenital third-degree heart block is unknown in most patients. Studies suggest that the prevalence of primary congenital third-degree heart block is between 1 in 15.000 and 1 in 22.000 live births.

Secondary CHB is one of the major complications of surgery for congenital heart disease. Although the incidence has decreased from $10 \%$ in the 1960 s to $1-3 \%$ in the current era, postoperative $\mathrm{CHB}$ remains a significant cause of morbidity, increased cost, and decreased longterm survival (1-4). Often the heart block is transient and further therapy is not required. In some cases, there is permanent damage of the conduction system and insertion of a permanent pacemaker (PM) is indicated (2). The highest incidence of CHB has been reported for surgical procedures involving a ventricular septal defect (VSD) or atrioventricular septal defect (AVSD), left ventricular outflow tract obstruction, or discordant atrioventricular (AV) connections (1, 5-9). In a study of postoperative AV conduction block, Weindling et al. reported that $95 \%$ of patients who have recovery of AV conduction do so by postoperative day 9 . They concluded that there was minimal benefit in delaying implantation of a permanent PM beyond 9 days when $\mathrm{CHB}$ was persistent (2). More recently, it has been suggested that patients

\footnotetext{
* Presented at the $11^{\text {th }}$ Belgian Surgical Week of the Royal Belgian Society for Surgery (RBSS), Ostend, Belgium, $28^{\text {th }}$ April to $1^{\text {st }}$ May, 2010 and nominated for the Young Investigators Award, the Annual Prize of the Royal Belgian Society for Surgery 2010.
} 
who have persistent complete AV block for even 24 to 48 hours following valve replacement should have PM implantation (10). Other studies have reported the late development of CHB months to years after surgery for congenital heart disease $(4,9,11,12)$. Conversely, the incidence and clinical significance of late recovery of AV conduction after CHB when PM implantation has been performed are not well known.

The purpose of this analysis was to determine the incidence of late recovery of $\mathrm{AV}$ conduction, the intermediate term follow-up of these patients, and factors potentially associated with recovery of $\mathrm{AV}$ conduction.

\section{Methods}

\section{Data acquisition.}

Data were collected prospectively and analyzed retrospectively. The surgical and PM databases were reviewed for patient characteristics, type of heart defect, surgery and AV-block at time of PM implantation, and postoperative timing of PM implantation. Between January 1977 and December 2008, a total of 56 patients underwent placement of a permanent PM for primary or secondary $\mathrm{CHB}$ at the University Hospitals Leuven, Belgium.

Electrocardiographic data were obtained from recorded rhythm strips, 12 lead surface electrocardiograms and Holter monitor recordings. Intracardiac electrophysiological data were not consistently available and therefore not included. Patients with placement of a permanent PM for sinus node dysfunction, high grade-second degree block or long QT syndrome bradycardia were excluded. The included patients were divided into two groups: those who remained PM dependent $(P D, n=54)$ and those in whom a recovery of $\mathrm{AV}$ conduction was seen $(\operatorname{Rec} A V, n=2)$. The PD patients included all patients with sustained CHB. The RecAV group comprised those patients who consistently demonstrated sinus rhythm on 12 lead surface electrocardiograms and/or Holter monitor recordings. The types of defect varied greatly for both PD and RecAV patients as did types of surgical repair and could not be singularly evaluated due to the small numbers. Values of continuous data are presented as a mean \pm standard deviation. However, the small number $(n=2)$ of the RecAV group does not allow further statistical analysis.

\section{Follow up}

Follow-up data were provided by both the department of pediatric cardiology and department of cardiac electrophysiology, University Hospitals Leuven, Belgium. No patients were lost to follow-up. Follow-up was obtained through semi-annually clinical reviews (unless clinically indicated sooner), where the underlying rhythm was examined. The longest follow-up period was 30.5 years (mean $9.85 \pm 9.62$ years for the PD group and $7.0 \pm 1.41$ for the RecAV group).

\section{Results}

\section{Patient data}

Table I shows patients with primary and secondary AV conduction block, divided into two groups : those who remained PM dependent and those in whom a recovery of AV conduction was seen. Indications for PM implantation could be categorized in primary $\mathrm{AV}$ conduction block ( $\mathrm{n}=28 ; 50 \%)$ and surgically-induced (secondary) AV conduction block $(\mathrm{n}=28 ; 50 \%)$.

Of the 56 patients identified, $2(3.6 \%)$ had recovered AV conduction and 54 (96.4\%) patients remained PM dependent (Table II). The PD and RecAV groups were almost similar for age at surgery $(8.5 \pm 15.3$ and $5.50 \pm$ 3.54 years) and age at PM implantation $(8.84 \pm 15.30$

Table I

Primary and secondary AV conduction block

\begin{tabular}{|c|c|c|}
\hline Total $(\mathrm{n}=56)$ & Pacemaker dependent & AV conduction recovery \\
\hline $\begin{array}{l}\text { Primary } \\
(\mathrm{n}=28)\end{array}$ & \begin{tabular}{|ll}
7 & Idiopathic \\
12 & maternal lupus \\
1 & maternal Sjögren \\
1 & maternal lupus + \\
& Sjögren \\
4 & L-TGA \\
2 & CAVC
\end{tabular} & 1 ASD II correction \\
\hline $\begin{array}{l}\text { Secondary }(\mathrm{n} \\
=28)\end{array}$ & $\begin{array}{ll}1 & \text { AVR + Contegra } \\
1 & \text { ASD I correction } \\
3 & \text { ASD II correction } \\
1 & \text { MVR } \\
4 & \text { CAVC } \\
1 & \text { L-TGA + ASD + VSD } \\
1 & \text { CoA } \\
1 & \text { CoA + subvalvular AS } \\
1 & \text { CoA + VSD } \\
1 & \text { L-TGA + VSD + DORV } \\
1 & \text { L-TGA + VSD + MR + TR } \\
1 & \text { redo-MVP } \\
1 & \text { TGA + DIRV-DORV + } \\
& \text { TAPVC } \\
1 & \text { TGA + VSD } \\
1 & \text { L-TGA + Ebstein + TR } \\
2 & \text { TOF } \\
4 & \text { VSD } \\
1 & \text { UVH + Ebstein + VSD }\end{array}$ & 1 MVR \\
\hline
\end{tabular}

L-TGA $=$ levo-transposition of the great arteries, $\mathrm{CAVC}=$ complete atrioventricular canal, AVR $=$ aortic valve replacement, $\mathrm{ASD}=$ atrial septal defect, ASD I = atrial septal defect type ostium primum, ASD II $=$ atrial septal defect type ostium secundum, MVR = mitral valve replacement, VSD = ventricular septal defect, $\mathrm{CoA}=$ Coarctation of the aorta, $\mathrm{AS}=$ aortic stenosis, $\mathrm{DORV}=$ double outlet right ventricle, $\mathrm{MR}=$ mitral regurgitation, $\mathrm{TR}=$ tricuspid regurgitation, $\mathrm{MVP}=$ mitral valve plasty, DIRV = double inlet right ventricle, TAPVC $=$ total anomalous pulmonary venous connection, TOF = tetralogy of Fallot, $\mathrm{UVH}=$ univentricular heart. 
and $5.59 \pm 3.42$ years), and had almost similar periods of follow-up (9.85 \pm 9.62 and $7.0 \pm 1.41$ years). The types of congenital heart defect and surgical repair were similar for both PD and RecAV groups.

\section{Electrocardiographic Data}

At the time of PM implantation, the two RecAV patients had CHB. The first patient was operated for atrial septal defect type ostium secundum with an intermittent CHB preoperatively. AV block resolved 2 days after PM implantation. The second patient underwent mitral valve replacement (MVR) for congenital mitral valve stenosis.

Postoperatively, the patient developed second degree heart block, which progressed 3 years later into CHB. A recovery of AV conduction was seen 7.5 years after PM implantation. In these patients, no late recurrence of $\mathrm{CHB}$ was found during follow-up (from AV conduction recovery) after 8 and 4 months, respectively.

Table III shows the characteristics of these two patients in whom a recovery of AV conduction was identified. Of note, the first patient experienced probably a transient $\mathrm{CHB}$, in which $\mathrm{AV}$ conduction resumed 2 days after PM implantation and the latter had already a significant morbidity associated with PM implantation in the pediatric population (lead fracture, PM generator replacement).

Table II

Patient characteristics

\begin{tabular}{|l|l|l|}
\hline & PD $(\mathrm{n}=54)$ & $\operatorname{RecAV}(\mathrm{n}=2)$ \\
\hline Age at surgery (yr) & $8.50 \pm 15.30$ & $5.50 \pm 3.54$ \\
Age at PM implantation $(\mathrm{yr})$ & $8.84 \pm 15.30$ & $5.59 \pm 3.42$ \\
Follow-up (yr) & $9.85 \pm 9.62$ & $7.0 \pm 1.41$ \\
\hline
\end{tabular}

$\mathrm{PD}=$ pacemaker dependent, RecAV = recovery of atrioventricular conduction, $\mathrm{PM}=$ pacemaker, $\mathrm{yr}=$ years.

\section{Timing of Implantation}

Although there was a larger number of patients in the PD group, there was similarity in either group as to the timing of PM implantation.

\section{Discussion}

Primary and secondary AV conduction system injury in congenital heart disease continues to be a leading cause of long-term cardiac morbidity. The incidence of postoperative AV conduction block has declined significantly since the necessity for PM implantation was first demonstrated by Lillehei et al. in 1963 (1). The impact of PM implantation on improving outcome of post-surgical CHB was borne by a number of subsequent retrospective reports $(5,8,13-15)$. Murphy et al. reported that approximately half of 40 patients who presented with CHB in the immediate postoperative period regained AV conduction, but this occurred within a month after surgery in most of them. Despite of their observation that CHB could have been responsible for death in $35 \%$ of their patients, they suggested that PMs should be used in children only rarely (8). Fryda et al. suggested that all children with permanent CHB after surgery should receive a PM because of the high mortality rate (67\%) observed in this group. Of note is that they reported a rate of AV conduction recovery of $62 \%$ in the first 3 weeks after surgery (13). Benrey et al. were the first to recommend PM implantation if postsurgical CHB persisted for more than 2 weeks (15). Driscoll et al. concluded that PM implantation should be performed if CHB persisted for more than 14 days and if the AV block was at, or below the level of the His bundle (5). The results of these studies form the basis for the current American College of Cardiology/American Heart Association/North American Society of Pacing and Electrophysiology

Table III

AV conduction recovery characteristics

\begin{tabular}{|l|l|l|}
\hline & $\begin{array}{l}\text { Primary }(\mathrm{n}=1) \\
\text { (ASD type ostium secundum) }\end{array}$ & $\begin{array}{l}\text { Secondary }(\mathrm{n}=1) \\
(\mathrm{MVR})\end{array}$ \\
\hline Age at surgery : & $3 \mathrm{yr}$ & $6.5 \mathrm{yr}$ \\
Age at PM implantation : & $3 \mathrm{yr}$ & $9.5 \mathrm{yr}$ \\
Height : & $102 \mathrm{~cm}$ & $125 \mathrm{~cm}$ \\
Weight : & $16.2 \mathrm{~kg}$ & $20.6 \mathrm{~kg}$ \\
BSA : & $0.67 \mathrm{~m}^{2}$ & $0.85 \mathrm{~m}^{2}$ \\
Location PM : & epigastric & epigastric \\
Leads : & 3 & 2 \\
Setting : & DDI & $7.5 \mathrm{year}$ \\
Recovery AV conduction : & 2 days & lead fracture \\
Postoperative problems : & - & 4 months \\
Follow-up from recovery : & 8 months & \\
\hline
\end{tabular}

$\mathrm{ASD}=$ atrial septal defect, $\mathrm{MVR}=$ mitral valve replacement, $\mathrm{PM}=$ pacemaker, $\mathrm{yr}=$ years, $\mathrm{BSA}=$ body surface area, $\mathrm{AV}=$ atrioventricular conduction. 
(ACC/AHA/NASPE) recommendations. They list "a postoperative advanced second- or third-degree AV block that is not expected to resolve or persists at least 7 days after cardiac surgery" as a class I indication for PM implantation (16-19).

Conversely, the notion that transient, spontaneously resolving CHB does not require permanent pacing is also broadly accepted, but its application is rendered less clear by the risk of late recurrence of CHB. Analysis of the available data suggests that spontaneous AV conduction recovery usually does take place within 7 to 10 days. However, late recovery of $\mathrm{AV}$ conduction is well recognized. A recovery of AV conduction in 7 in $72(9.6 \%)$ cases of postoperative CHB persisting beyond 14 days was reported by Batra et al. (20). Recovery was noted at postoperative time points ranging up to 113 days (median 41 days). Bruckheimer et al. identified very late recovery of AV conduction up to 20 years (median 5.5 years) after onset of CHB in 14 (32\%) of 44 patients who had undergone PM implantation. They were unable to identify any factors predictive of recovery (21).

Our study results indicate that $3.6 \%$ of patients who underwent PM implantation for CHB had regained permanent AV conduction at mean follow-up of 7.0 years. We could not accurately assess the exact timing of recovery of AV conduction due to the retrospective nature of the study. This is certainly a limitation of the study. However, the underlying rhythm is routinely assessed in PM follow-up clinic visits. Recovery could not be predicted from the retrospective data on patient characteristics, type of heart defect or type of repair.

Several investigators have attempted to identify additional prognostic predictors in CHB. Attention has focused on the anatomic site of conduction system disruption. Driscoll et al. took an invasive approach, categorizing the level of block as being above, at, or below the bundle of His (supra-, intra- or infrahisian block) based on intracardiac recordings obtained in 14 patients. Spontaneous recovery occurred most often ( $3 / 5$ patients) among those with supra-hisian block, whereas conduction returned in one of four patients with infra-hisian block, none of two who had block within the His bundle, and three of three who had block at an indeterminate level (5).

An escape rhythm QRS complex morphology in CHB with that observed following recovery of conduction at a mean of 7.3 postoperative days was compared by Nishimura et al. They found no late recurrences during 2.5 to 10 years of follow-up among nine patients whose escape rhythm QRS complex morphology matched that seen after recovery. However, two of four patients with discordant QRS morphology subsequently experienced heart block recurrence at 2 and 48 months. Their interpretation of this interesting observation was that infrahisian block would more likely be associated with escape rhythm QRS complex morphology dissimilar to that seen following recovery than would be the case if transient block occurred more proximally in the conduction system (22).

A meta-analysis of the prognostic significance of electrocardiographic fascicular block patterns following surgery for congenital heart disease was performed by Krongrad. He concluded that the location and degree of conduction system injury likely do carry some prognostic significance in patients with transient postoperative heart block $(23,24)$.

\section{Conclusion}

Our findings do not contradict the current recommendations and we did not find evidence for not implanting PMs in patients who regained AV conduction. Recovery of AV conduction was observed in one patient with primary AV conduction block and in one patient with complete heart block after congenital heart surgery. However, this raises issues of both short and long-term management. A pertinent clinical problem is presented by those permanently paced patients with recovered AV conduction who are due for elective generator replacement. Lifelong cardiac pacing in these specific subsets of patients may not be necessary. The limited number of patients in this study requires that these findings be verified by similar studies before a general recommendation can be made. Conversely, it is important to recognize that AV conduction did not recover in $96.4 \%$ of patients and that recovery could not be predicted based on clinical variables given the limited number of patients in this series. Consistent with current AHA/ACC Guidelines, we advocate that a PM be implanted in patients with persistent CHB lasting for 7 to 10 days. Furthermore, we suggest to continue monitoring patients who regain $\mathrm{AV}$ conduction, to establish criteria for pacing following recovery of $\mathrm{AV}$ conduction, and to perform electrophysiological tests to establish guidelines for long-term PM dependency.

\section{References}

1. Lillehei C. W., Sellers R. D., Bonnabeau R. C., Elliot R. S. Chronic postsurgical complete heart block with particular reference to prognosis, management and a new P-wave pacemaker. $J$ Thorac Cardiovasc Surg, 1963, 46 : 436-56.

2. Weindling S. N., Saul P. J., Gamble W. J., Mayer J. E., Wessel D., Walsh E. P. Duration of complete atrioventricular block after congenital heart disease surgery. Am J Cardiol, 1998, 82 : 525-7.

3. Bonatti V., Agnetti A., Squarcia U. Early and late postoperative complete heart block in pediatric patients submitted to open-heart surgery for congenital heart disease. Ped Med Chir, 1998, 20 : 1816.

4. Hokanson J. S., Moller J. H. Significance of early transient complete heart block as a predictor of sudden death late after operative correction of tetralogy of Fallot. Am J Cardiol, 2001, 87 : 1271-7.

5. Driscoll D. J., Gillette P. C., Hallman G. L., Cooley D. A., McNamara D. G. Management of surgical complete atrioventricular block in children. Am J Cardiol, 1979, 43 : 1175-80. 
6. Hurwitz R. A., Riemenschneider T. A., Moss A. J. Chronic postoperative heart block in children. Am J Cardiol, 1968, 21 : 185-9.

7. Liu L., Griffeths S. P., Gerst P. H. Implanted cardiac pacemakers in children : a report of their application in five patients. Am J Cardiol, 1967, 20 : 639-47.

8. Murphy D. A., Tynan M., Graham G. R., Bonham-Carter R. E. Prognosis of complete atrioventricular dissociation in children after open-heart surgery for congenital heart defects. Lancet, 1970, I : 750-2.

9. Seuarcia U., Merideth J., McGoon D. C., Weidman W. H. Prognosis of transient atrioventricular conduction disturbances complicating openheart surgery for congenital heart defects. Am J Cardiol, 1971, 28 : 648-52.

10. Kim M. H., Deeb G. M., Engle K. A. et al. Complete atrioventricular block after valvular heart surgery and the timing of pacemaker implantation. Am J Cardiol, 2001, 87 : 649-51.

11. Moss A. J., Klyman G., Emmananoulides G. C. Late onset complete heart block: newly recognized sequela of cardiac surgery. Am J Cardiol, 1972, $30: 884$.

12. Banks MA, Jenson J, Kugler JD. Late development of atrioventricular block after congenital heart surgery in Down syndrome. Am J Cardiol. $2001 ; 88: 86-8$.

13. Fryda RJ, Kaplan S, Helmsworth JA. Post operative complete heart block in children. Br Heart J. 1971 ; 33 : 456-62.

14. Stanton RE, Lindesmith GG, Meyer BW. Pacemaker therapy in children with complete heart block. Am J Dis Child. 1975; 129 : 484-87.

15. Benrey J., Gillette P. C., Nasrallah A. T., Hallman G. L. Permanent pacemaker implantation in infants, children and adolescents. Long term follow-up. Circulation, 1976, 53 : 245-48.

16. Dreifus L. S., Fisch C., Griffin J. C., Gillette P. C., Mason J. W., PARSONNET V. Guidelines for implantation of cardiac pacemakers and antiarrhythmia devices. A report of the American College of Cardiology/American Heart Association Task Force on Assessment of Diagnostic and Therapeutic Cardiovascular Procedures. (Committee on Pacemaker Implantation). J Am Coll Cardiol, 1991, 18 : 1-13 and Circulation, 1991, 84 : 455-67.

17. Gregoratos G., Cheitlin M. D., Conill A. et al. ACC/AHA guidelines for implantation of cardiac pacemakers and antiarrhythmia devices. A report of the American College of Cardiology/American Heart Association Task Force on Practice Guidelines (Committee on Pacemaker Implantation). J Am Coll Cardiol, 1998, 31 : 1175209.

18. Gregoratos G., Abrams J., Epstein A. E. et al. ACC/AHA/NASPE 2002 guideline update for implantation of cardiac pacemakers and antiarrhythmia devices: summary article: a report of the American College of Cardiology/American Heart Association Task Force on Practice Guidelines (ACC/AHA/NASPE Committee to Update the 1998 Pacemaker Guidelines). Circulation, 2002, 106 : 2145-61.

19. Epstein A. E., DiMarco J. P., Ellenbogen K. A. et al. ACC/AHA/ HRS 2008 Guidelines for Device-Based Therapy of Cardiac Rhythm Abnormalities: a report of the American College of Cardiology/American Heart Association Task Force on Practice Guidelines (Writing Committee to Revise the ACC/AHA/NASPE 2002 Guideline Update for Implantation of Cardiac Pacemakers and Antiarrhythmia Devices) : developed in collaboration with the American Association for Thoracic Surgery and Society of Thoracic Surgeons. Circulation, 2008 , 117 : 350-408.

20. Batra A. S., Wells W. J., Hinoki K. W., Stanton R. A., Silka M. J. Late recovery of atrioventricular conduction after pacemaker implantation for complete heart block associated with surgery for congenital heart disease. J Thorac Cardiovasc Surg, 2003, 125 : 1291-3.

21. Bruckheimer E., Berul C. I., Kopf G. S. et al. Late recovery of surgically-induced atrioventricular block in patients with congenital heart disease. J Interv Card Electrophysiol, 2002, 6 : 191-5.

22. Nishimura R. A., Callahan M. J., Holmes D. R. et al. Transient atrioventricular block after open-heart surgery for congenital heart disease. Am J Cardiol, 1984, 53 : 198-201.

23. Krongrad E. Prognosis for patients with congenital heart disease and postoperative intraventricular conduction defects. Circulation, 1978, $57: 867-70$.

24. Gross G. J., Chiu C. C., Hamilton R. M., Kirsh J. A., STEPHENSON E. A. Natural history of postoperative heart block in congenital heart disease: implications for pacing intervention. Heart Rhythm, 2006, $3: 601-4$.

\section{J. De Raet, MD}

Department of Cardiac Surgery

University Hospitals Leuven

Herestraat 49

B-3000 Leuven, Belgium

Tel. + 3216344260

Fax. + 3216344616

E-mail : jan.deraet@uzleuven.be 